\title{
Murcha-de-Ceratocystis em Acácia-Negra no Brasil
}

\author{
Álvaro F. dos $\operatorname{Santos}^{1}$ \& Francisco A. Ferreira ${ }^{2}$ \\ ${ }^{1}$ Embrapa Florestas, Estrada da Ribeira Km 111, Cx. Postal 319, CEP 83411-000, Colombo, PR, e-mail: alvaro@cnpf.embrapa.br; \\ ${ }^{2}$ Universidade Federal de Viçosa, Departamento de Fitopatologia, 36571-000, Viçosa, MG, e-mail: ffff@mail.ufv.br
}

(Aceito para publicação em 18/03/2003)

Autor para correspondência: Álvaro Figueredo dos Santos

\section{ABSTRACT}

\section{Ceratocystis wilt of black wattle in Brazil}

This paper reports the occurrence of Ceratocystis fimbriata causing wilt and tree mortality of black wattle (Acacia mearnsii) in two-three-year-old plantations in the State of Rio Grande do Sul, Brazil, during 2001. Ceratocystis wilt is recorded for the first time in black wattle in Brazil.

\section{fimbriata.}

No teste de patogenicidade, inocularam-se plantas de em grande escala no Brasil, especialmente no Estado do Rio Grande do Sul, onde a casca é destinada à produção de tanino e a madeira para celulose e energia. A área plantada está estimada em 100.000 ha. Em 2001, em plantios de acácia negra com dois a três anos de idade, nos municípios de Triunfo e Tupandi-RS, verificaram-se árvores com sintoma de murcha seguida de morte. Quando os caules foram seccionados transversalmente, observaram-se internamente estrias radiais marrom-escuras no cerne. Amostras de caules, com as estrias mencionadas, foram coletadas e colocadas em câmaras úmidas. Duas semanas após, observou-se abundante produção de peritécios caracterizados por sua base globosa, de onde partia longo rostro, cuja porção apical era rodeada por hifas ostiolares, onde se verificava a exsudação constituída de ascósporos. Os ascos eram evanescentes, com ascósporos hialinos, de parede lisa, unicelulares, em forma de chapéu, característicos da espécie Ceratocystis fimbriata Ell. \& Halst (Arx, The Genera of Fungi Sporulating in Pure Culture, 1970). Um isolado do fungo foi obtido em meio de cultura batata-dextrose-ágar (BDA), a partir de mucilagem ascospórica dos ápices dos ostíolos e por meio de iscas de cenoura (Daucus carotae L.). Cada isca foi constituída de dois discos de $5 \mathrm{~mm}$ de altura, entre os quais se depositaram fragmentos de lenho com os sintomas. Em seguida, as iscas foram envolvidas com plástico transparente e incubadas em caixas de plástico gerbox, contendo papel de filtro umedecido com água destilada e esterilizada. Após 15 dias de incubação, em condições de ambiente de laboratório, foram observados peritécios de $C$. acácia-negra com um ano de idade. Discos de casca de $5 \mathrm{~mm}$ de diâmetro foram retirados a cerca de $10 \mathrm{~cm}$ do colo, preenchendo a injúria com disco de cultura de $C$. fimbriata $\mathrm{em}$ BDA, com dez dias de idade. Em seguida, a área inoculada foi recoberta com fita adesiva. Dez plantas foram inoculadas com C. fimbriata e dez receberem discos de BDA sem o fungo. Das plantas inoculadas com o fungo, $70 \%$ apresentaram sintomas de murcha, seguida de morte. As plantas testemunhas permaneceram crescendo normalmente, sem os sintomas da doença.

Ceratocystis fimbriata é um patógeno polífago, de ampla distribuição geográfica, que afeta culturas de importância econômica, como cacaueiro (Theobroma cacao L.), cafeeiro (Coffea arabica L.), mangueira (Mangifera indica L.) e eucalipto (Eucalyptus spp.) (Ribeiro et al., Bragantia, 1988; Kimati et al., Manual de Fitopatologia, 1997).

No Brasil, a ocorrência de doença causada por $C$. fimbriata somente havia sido registrada em Acacia decurrens Wild. em 1988 acarretando mortalidade de plantas na região de Capão Bonito, São Paulo (Ribeiro et al., Bragantia, 1988). Em acácia-negra, murcha e mortalidade de árvores causada por C. albofundus De Beer, Wingfield \& Morris foi descrita na África do Sul (Roux et al., South African Forest Journal, 1995). Deste modo, a ocorrência de C. fimbriata causando morte de árvores de A. mearnsii no RS constitui-se no primeiro relato da doença murcha-de-Ceratocystis em acácia-negra no Brasil. 